\title{
ROBUSTNESS, REPEATABILITY AND RESILIENCE OF INTERCONTINENTAL DISTRIBUTED COMPUTING FOR THE PURPOSES OF SEISMIC ASSESSMENT OF BRIDGES
}

\author{
Olympia N. Taskari ${ }^{1}$, Anastasios G. Sextos ${ }^{2}$ \\ ${ }^{1}$ Aristotle University of Thessaloniki, Greece, Ph.D. Student \\ e-mail: taskari@civil.auth.gr \\ ${ }^{2}$ Aristotle University of Thessaloniki, Greece, Assistant Professor \\ asextos@civil.auth.gr
}

Keywords: Multi-platform simulation, geographical distributed simulation, SimCor

\begin{abstract}
Hybrid simulation is a promising tool that permits the integration of different laboratories in real time to undertake a set of joint experiments on individual components assembling a structural system. The components studied either analytically or experimentally can be physically distributed and thus potentially located anywhere. The same concept has also been applied for the numerical coordination of distributed sub-structures in the framework of multi-platform simulation. The advantage of the latter approach is that it permits the use of different numerical analysis packages, enabling the concurrent use of the most sophisticated constitutive laws, element types and features that each specialized software provides for each individual part of the system. Notwithstanding the major advancements made so far in hybrid experimentation, it is notable that the vast majority of such trans-laboratory campaigns has taken place within the U.S. The scope of this paper therefore, is to present the recent findings and technical challenges encountered in an attempt to run similar (hybrid and multi-platform) experiments both within Europe and between E.U. and the U.S. for the study of seismic soil-structure interaction effects in bridge structures. The paper also discusses the parameters that were found to affect the efficiency and repeatability of distributed analysis while it investigates the resilience of the procedure in cases of abrupt network failure. It also foresees the conditions under which the implementation of a geographically distributed hybrid simulation is indeed feasible, robust and repetitive between transatlantic partners. For this scope, the seismic response of a $110 \mathrm{~m}$ long, four span, reinforced concrete bridge is preliminary assessed, through its numerical sub-structuring into five structural components (modules) that are analyzed in computers located in the cities of Thessaloniki (Greece), Patras (Greece), Naples (Italy), Urbana-Champaign (U.S.), and Toronto (Canada). The analyses results as well as the implications of the parameters involved in the feasibility of an intercontinental hybrid experiment are also critically discussed.
\end{abstract}




\section{INTRODUCTION}

Experimental methods or analytical models can be used for the seismic evaluation of structures. Despite the increasing capabilities of the laboratories, parameters related with space or equipment capacity limit the full-scale testing of the entire structures. On the other hand, analytical methods cannot fully capture the real complex seismic behavior of the modeled structures inducing an uncertainty level which in many cases cannot be neglected. The combination of the experimental and analytical methods is a very promising tool introduced as hybrid simulation.

Specifically, a number of laboratories could combine their capabilities to undertake a set of integrated component tests of structures. In fact, this multi-site, Real Time Hybrid Simulation (RTHS) approach has already been developed in the United States for the assessment of complex interacting systems. It is supported by NSF through the Network for Earthquake Engineering Simulation (NEES, www.nees.org) scheme [1-4] and it aims to raise the limitations related to the laboratory capacities. In this framework, there is no need for using a single experimental facility neither there is need for physical proximity of the multiple subcomponents tested. Moreover, since communication is solely web-based, using the same protocols, some components of the system can be analyzed numerically while others can be physically tested. The dynamic response of full scale specimens that are discretized into substructures is properly controlled with the use of purpose-specific coordination software. Two such specialized software platforms exist to date, i.e. the OpenFresco [5-6] and SimCor [7]. The components (analytical, experimental or a combination of both) are treated on different networked computers and, can thus be located anywhere in the world. Another major advantage of hybrid simulation is that it removes a large source of uncertainty compared to pure numerical simulations, by replacing structural elements with complex non-linear behavior with physical specimens tested on the laboratory floor. Apparently, drawbacks also exist and are related to the necessity for in-depth knowledge of specialized experimental and analytical tools as well as for considerable programming effort and computational cost.

The same concept has also been successfully applied [8] for the coordination of purely numerical analysis modules (where no physical testing is performed, in contrast to the hybrid simulation application). This, so called, "multi-platform simulation" is another promising alternative to the aforementioned hybrid simulation approach primarily because it permits the sub-structured analysis of a complex system using purely analytical tools, similarly physically distributed as was the previous case. The advantage of this approach is that the appropriate selection and combination of different analysis packages, enables the concurrent use of the most sophisticated constitutive laws, element types and features of each package for each corresponding part of the system. In other words, different software can be used for different system components (i.e. abutments, superstructure and supporting pile groups for instance in the case of a long bridge), depending on the foreseen inelastic material behavior, level and nature of the seismic forces and the geometry of the particular problem. It is believed that this approach leads to combined capabilities that no finite element program currently provides, nor is it probable to provide in the near future. On the contrary, it has the minimum assumptions possible and permits the best available option to simulate each component using the most appropriate analytical model, while integrating the various contributions into a fully interacting system. As for the case of Hybrid Simulation though, the computational cost and level of expertise is relatively high compared to a conventional all-inclusive simulation package.

The EU Framework 7 project, EXCHANGE-SSI, enables a number of earthquake engineering centers in Europe and the U.S to collaborate on the application of distributed, 
hybrid or multi-platform experimentation for the study of seismic soil-structure interaction effects in bridge structures. In this framework, a four span seismically isolated reinforced concrete bridge of a total length of $110.40 \mathrm{~m}$ was selected to be assessed by implementing the geographically distributed simulation concept. Although this approach has been used by several research groups, in most cases, the experimentally tested component was a reinforced concrete or a steel structural member. However, in the case of the EXCHANGE-SSI project, it is a rate-dependent member (i.e., bearing) that is to be experimentally tested. In this case, the required time for the communication among the modules is the most critical parameter for the successful conduct of the hybrid experiment.

The scope of this study is therefore, to optimize the parameters that delay the distributed analysis as well as to investigate the conditions under which the implementation of a geographically distributed hybrid simulation concept becomes robust, repetitive and resilient in the case of an intercontinental experiment. For this purpose, it was deemed necessary, before proceeding with hybrid experimentation, to implement a first multi-platform analysis simulation for the system studied. Along these lines, the bridge was divided into four structural components (modules), each one being analyzed using specific software in a different computer station located in Aristotle University of Thessaloniki (AUTH), University of Patras (UPATRAS), University of Illinois at Urbana Champaign (UIUC), University of Naples (UNAPLES) and University of Toronto (UTR). In the subsequent stage, the bearing will be physically tested at the University of Patras, thus replacing the computational node with an experimental component. In both cases, the SimCor [10] communication platform was used as the analysis coordinator (Figure 1). Clearly such a five-partner, intercontinental hybrid experiment is a challenging task which has only limited applications so far, the only successful known to the authors being the specimen test between two UC Berkeley and University of Kassel in Germany [9].A full description of the analytical sub-structured modules, the parametric scheme followed for the optimization of the distributed simulation in terms of computational cost, the analyses results as well as the limitations and future developments are discussed in the following.

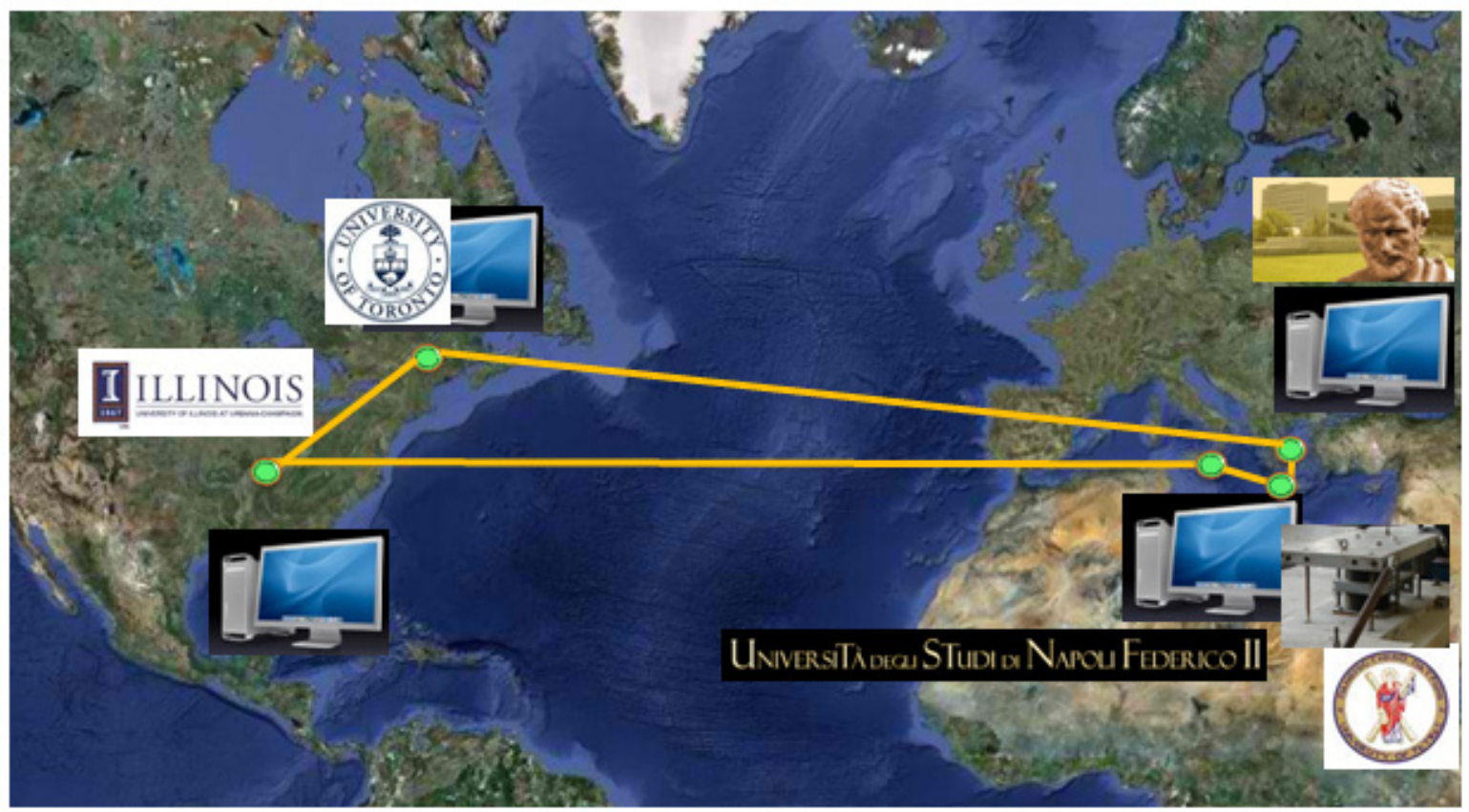

Figure 1: Geographical distributions of the numerical and experimental sub-structures involved in the multi-platform and hybrid experiments (www.exchange-ssi.net). 


\section{OVERVIEW OF THE CASE STUDIED}

The seismic evaluation of a four span reinforced concrete bridge of a total length of $110.40 \mathrm{~m}$ was selected for the particular study. The bridge is located in the region of northeastern Greece and is part of the perpendicular EGNATIA highway axis connecting Greece and Bulgaria. The two outer spans have a $24.20 \mathrm{~m}$ length each, while the two inner spans have a $31.00 \mathrm{~m}$ length. A prestressed hollow deck is supported on two piers which consist of circular reinforced concrete sections of a diameter equal to $2.0 \mathrm{~m}$. Two series of $65 \varnothing 25$ longitudinal bars spaced equally around the perimeter were used for the piers. For the transverse reinforcement, a double $\varnothing 14$ spiral at $8.5 \mathrm{~cm}$ was used throughout the entire pier length $(5.85 \mathrm{~m})$. A bearing type pier-to-deck connection was adopted permitting movement along the two principal, longitudinal and transverse direction. For each pier-to-deck connection, two 900x900x328 ALGABLOC NB4 bearings were used computed according to the Greek seismic code for bridges, E39/99 [11] and the relevant DIN4141 specifications. The deck is supported on seat type abutments with a backwall height equal to $1.5 \mathrm{~m}$. At the abutments, the deck is connected through two pot bearings that permit sliding along the two principal bridge axes, while a sliding joint of $22 \mathrm{~cm}$ length separates the deck from the backwall. Seismic forces are also resisted by the activation of stoppers (activated in the transverse direction) located at the seating of the abutments. A general overview of the bridge configuration and the deck section at various locations are illustrated in Figures 2-3.

The foundation is deep due to the soft soil formations existing in the overall area. The presence of loose cohesionless saturated soil deposits, the low $\mathrm{N}_{30}$ values measured in the loose silty sand layers and the high water table level are evidence of liquefaction susceptibility. For this purpose, a group of gravel piles of a diameter equal to $0.80 \mathrm{~m}$ was constructed in the area, at a depth that was determined from the SPT and CPT results. Consequently, the piers and the abutments are supported on $1.2 \mathrm{~m}$ diameter group of piles (3x2) with a total length equal to $32.00 \mathrm{~m}$ that cross the liquefaction susceptible layers until the healthy sand formations are reached.

The Greek Seismic Code [12] that was put into force at the time of design, prior to the introduction of Eurocodes, prescribed a peak ground acceleration of $0,24 \mathrm{~g}$ and soil class " $\mathrm{C}$ " which are identical to the ones defined in Eurocode 8 - Part 2, for bridge design [13]. The importance factor was set equal to 1.0, while the behavior (or force reduction) factor was also selected equal to unity, since the bridge under study is seismically isolated, thus, no ductile behavior at the reinforced concrete pier members is anticipated for the design earthquake.

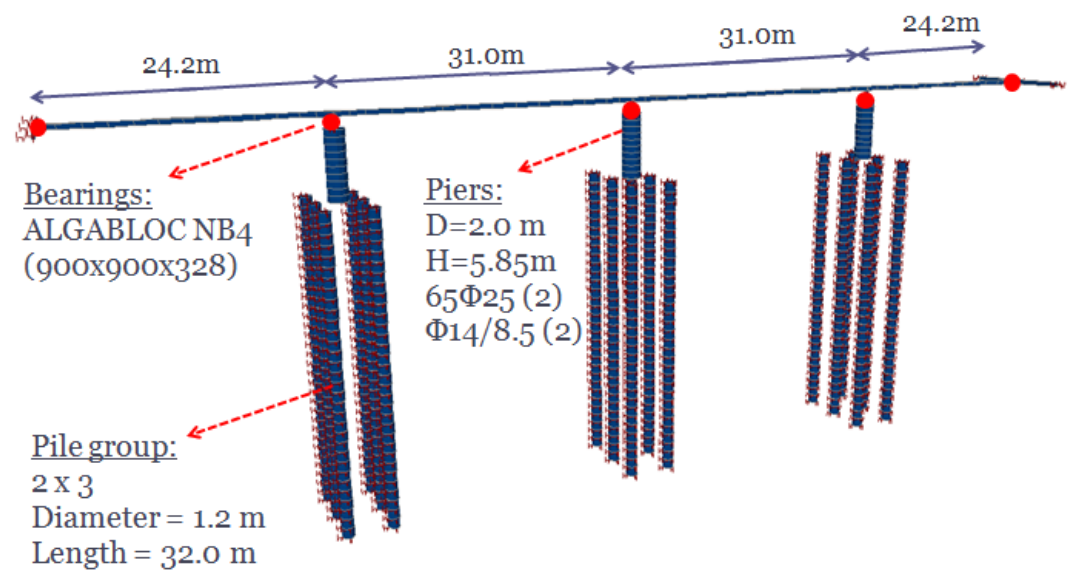

Figure 2: Layout of the bridge configuration. 

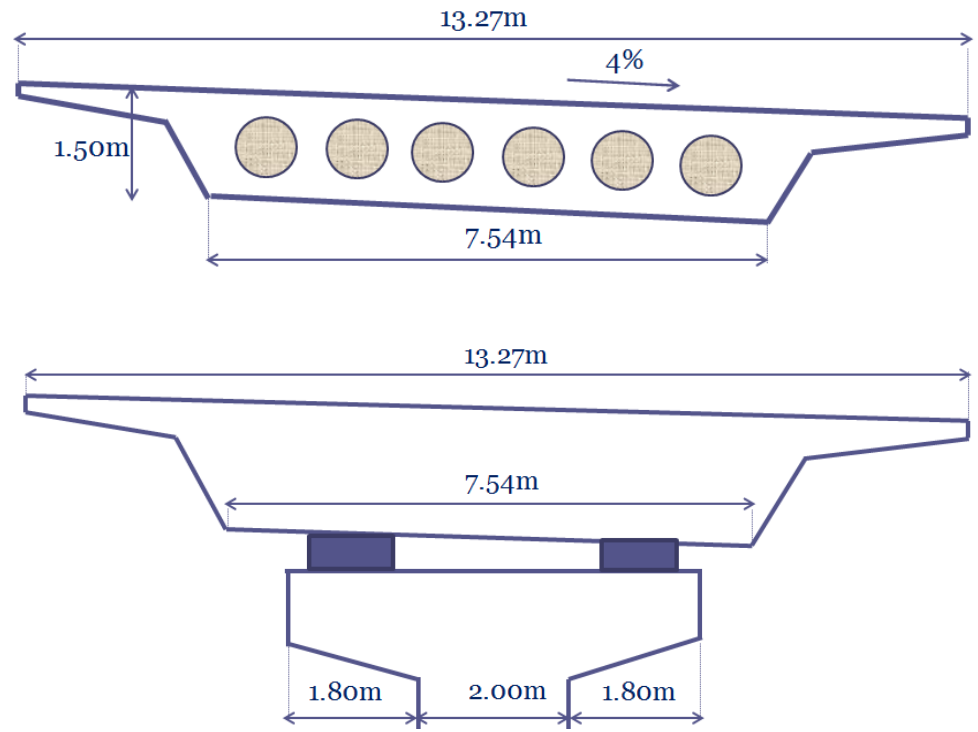

Figure 3: Deck section at the middle of the span (top) and at the location of the piers (bottom).

\section{MULTI-PLATFORM ANALYSIS}

The specialized software platform SimCor [7] developed by the research group of the University of Illinois was used for coordinating the preliminary multi-platform analysis used to optimize the envisaged hybrid experiment. SimCor concerns an enhanced Matlab-based script which coordinates software or hardware components supporting the NEESgrid Teleoperation Control Protocol (NTCP), as well as TCP-IP connections outside of the NEES system. The basic concept of SimCor is that analytical models of some parts of the structure or experimental specimens representing specific parts of the same structure, are all considered as super-elements with many DOFs. Specially developed interface programs permit the interaction with different analysis software such as Zeus-NL [14], OpenSees [15], FedeasLab [16], and ABAQUS [17]. After the initialization step where the connection between the modules is achieved, the stiffness matrix of the whole structure is evaluated using predefined deformation values. The gravity forces are considered during the static loading stage where displacements due to gravity forces are imposed. Finally, SimCor performs Newmark numerical integration as it steps through the seismic record by utilizing the OS method with a modified $\alpha$ - parameter (a-OS method) which applies numerical damping to the undesired oscillations.For the purpose of the EXCHANGE-SSI program, the bridge under study is substructured into an number of modules which are analyzed in different computer stations located at different institutes (AUTH, UPATRAS, UNAPLES, UIUC, UTR). An overview of the distinct modules is provided below.

\subsection{Description of the multi-platform simulation modules}

The four-span reinforced concrete bridge was divided into four different components (modules) each one analyzed in a different computer station after appropriate definition of the control points at the joint DOFs of interest. At each analysis step, a predefined displacement was imposed by the analysis coordinator and forces were measured to each specific module to establish the initial stiffness matrix of the sub-structured system. The established matrix is then used in the static and dynamic loading stage to determine the desirable target displacements. A brief description of the four modules is illustrated in Figure 4 and is presented in the following. 
- Module1@UTR: Consists of the 110.40m bridge deck along with the middle and the right pier and the corresponding two bearings, all modeled and analyzed using the OpenSees software. The superstructure is expected to remain linear and is thus modeled using linear elastic beam-column elements, while fiber sections with distributed plasticity are used for the piers. Each fiber of the cross-section is modeled with an appropriate stress-strain relationship depending on whether it represents confined concrete, unconfined concrete or a longitudinal reinforcing bar. The median design strength of concrete and the yielding strength of reinforcing steel are taken equal to 38 and $550 \mathrm{MPa}$, respectively. The bearings are modeled using the elastomeric bearing element where the initial stiffness is calculated using the geometry of the pad [18]. In this study, the right abutment-embankment system (described in the following) initially modeled using solid elements, is represented as a set of 6-DOF linear springs and is considered as part of the same module.

- Module2@UPAT: The bearings connecting the left pier to the deck is considered as an individual module and is modeled as an elastomeric bearing element whose initial stiffness is calculated by the geometry of the pad [18]. The same module will be used to link the actual bearing, to be experimentally tested at the University of Patras during hybrid simulation.

- Module 3 @UIUC: The abutment-embankment system is simulated using the OpenSees software, through solid elements but again considered herein as non-linear translational springs. The stiffness of the springs is a function of the passive resistance of the soil as well as the stiffness of the abutment foundation piles. In fact, the backwall is intended to break off and mobilize the longitudinal resistance of the approach fill [13-14] in order to protect the foundation from excessive deformations and distress. Therefore, the backwallbackfill interaction, as well as the passive earth resistance behind the abutments, that is, by design, the main mechanisms activated during a strong seismic event are considered according to the recent literature [21].

- Module 4 @UNAP: The left pier, below the critical bearing is also deemed as an individual module numerically analyzed with OpenSees using fiber sections as previously.

- Analysis Coordinator @AUTH: As previously mentioned, the integration of the analytical modules is conducted in SimCor.

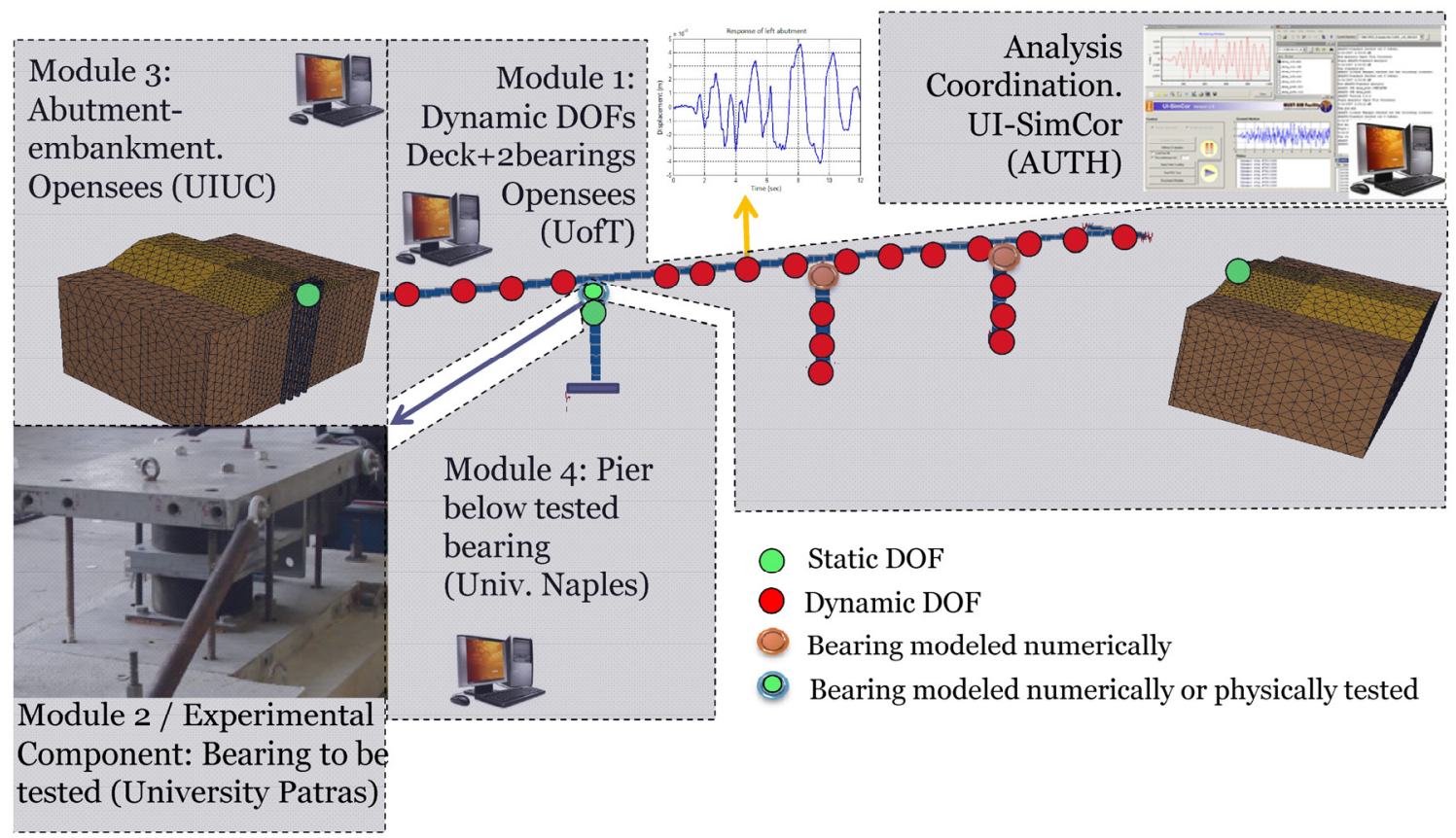

Figure 4: Layout of the bridge substructuring. 


\subsection{Robustness of the multi-platform model}

For comparison purposes, the bridge was also modeled as a whole in OpenSees in order to ensure that the multi-platform analysis yields similar results to that of the full model. The two models were subjected to the same artificial input motion that matched the target Eurocode 8 design spectrum. The force-displacement loops of the middle bearing for the sub-structured and the entire model are presented in Figure 5. It is observed that, despite the system substructuring to modules widespread all over the world, there is an excellent match between the two models and therefore the multi-platform scheme is deemed an acceptably robust method for analysis and assessment.

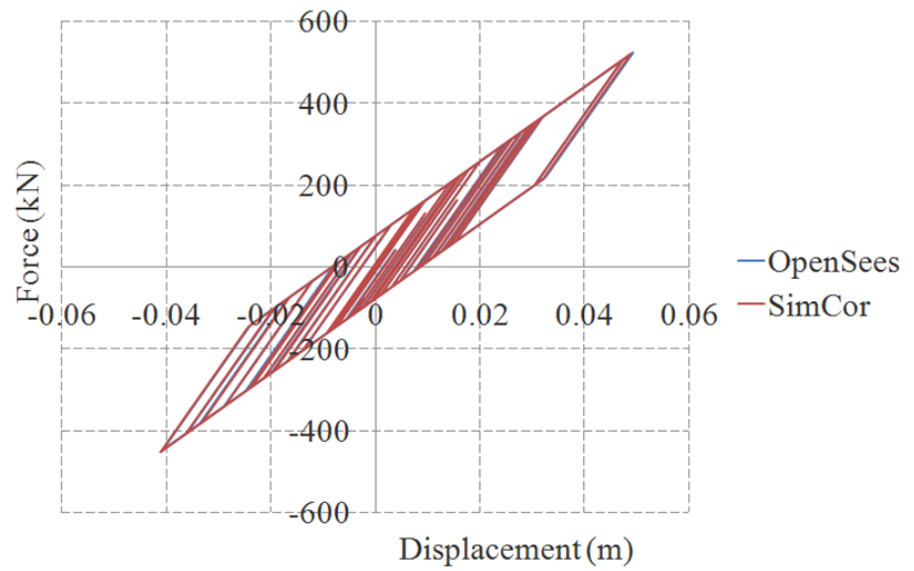

Figure 5: Comparison of the force-displacement loops between the full and the sub-structured model.

\section{CONDITIONS FOR AN INTERCONTINENTAL MULTI-PLATFORM AND HYBRID EXPERIMENT}

Having established a level of confidence regarding the ability of the multi-platform analysis to represent the non-linear behavior of the bridge structure, a parametric analysis scheme was implemented in order to investigate the conditions under which an intercontinental geographically distributed hybrid simulation becomes robust and repetitive. More specifically, an effort was made to decide whether the analysis time depends on the geographically distributed scheme adopted among the five partners. For this scope, different modules were assigned to each partner at all possible combinations, while retaining the analysis coordination role at AUTH. The distributed parametric scheme and the required analysis time for each run are summarized in Table 1. It is seen that the total analysis time, indeed varies between 45 and 65 minutes for the entire seismic excitation time window, despite the fact that the sub-structured modules are in all cases identical.

In a similar parametric manner, the importance of the time zone was also investigated. Figure 6 presents the average analysis time as a function of the Greek time zone in which the multi-platform analysis tool place. It can be noticed that due to network traffic, different execution times lead to different analysis time, inducing a coefficient of variation of approximately $15 \%$ to the analysis time. It is also notable that the most favorable time for conducting the intercontinental multi-platform simulation is between 2:00am-4:00am and 12:00 and 14:00pm Greek time, essentially corresponding to off-peak networking times for the American partners. 


\begin{tabular}{|l|c|c|c|c|c|}
\hline AUTH & UIUC & U of T & UPATRAS & UNAPLES & Time (min) \\
\hline SimCor & Module 1 & Module 2 & Module 3 & Module 4 & 47 \\
\hline SimCor & Module 1 & Module 3 & Module 4 & Module 1 & 47 \\
\hline SimCor & Module 1 & Module 4 & Module 1 & Module 2 & 45 \\
\hline SimCor & Module 2 & Module 1 & Module 3 & Module 4 & 65 \\
\hline SimCor & Module 2 & Module 3 & Module 4 & Module 1 & 57 \\
\hline SimCor & Module 2 & Module 4 & Module 1 & Module 3 & 54 \\
\hline SimCor & Module 3 & Module 1 & Module 2 & Module 4 & 54 \\
\hline SimCor & Module 3 & Module 2 & Module 4 & Module 1 & 65 \\
\hline SimCor & Module 3 & Module 4 & Module 1 & Module 2 & 48 \\
\hline SimCor & Module 4 & Module 1 & Module 2 & Module 3 & 54 \\
\hline SimCor & Module 4 & Module 2 & Module 3 & Module 1 & 65 \\
\hline SimCor & Module 4 & Module 3 & Module 4 & Module 2 & 56 \\
\hline
\end{tabular}

Table 1: Parametric analysis of partners' roles and overall analysis time during the geographically distributed seismic analysis of the bridge studied.

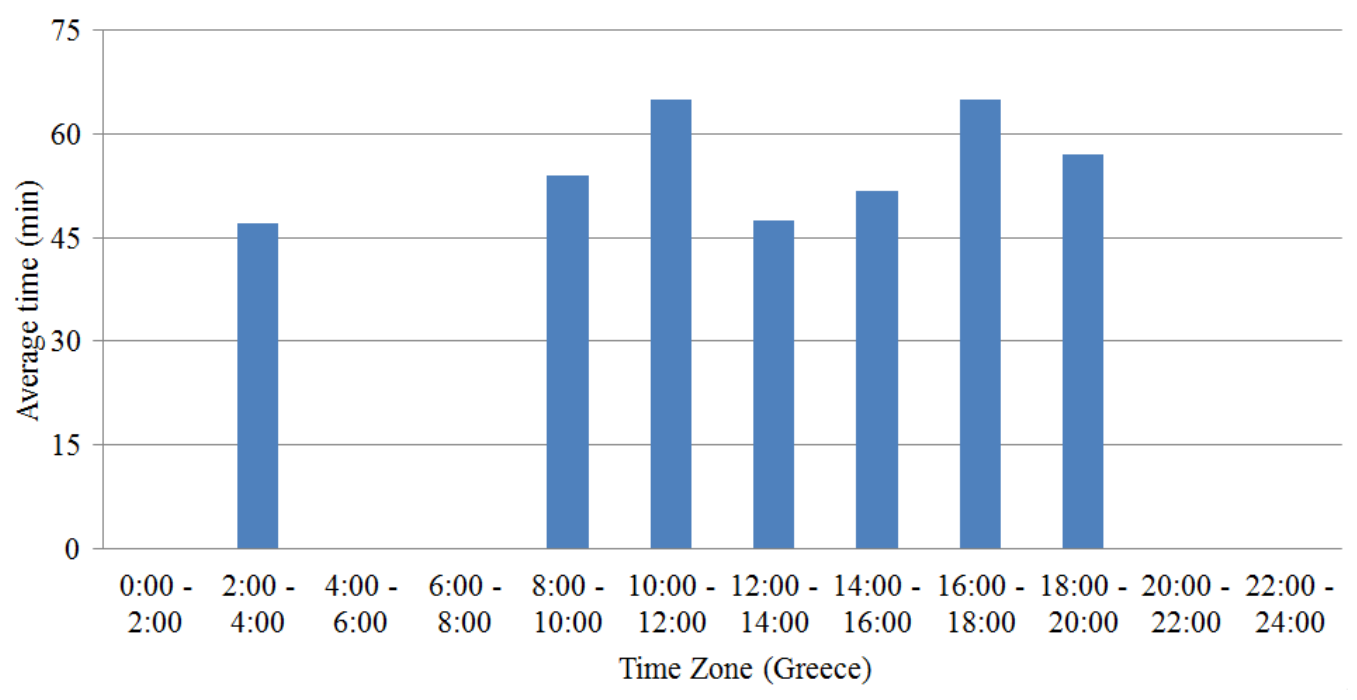

Figure 6: Effect of the analysis time window on the overall time analysis daytime during the geographically distributed analysis.

After deciding the optimum distributed simulation scheme and the most efficient time window of analysis, an effort was made to determine the relative contribution of all the parameters affecting the computational cost, i.e. (i) finite element analysis - related time (Opensees) (ii) module coordination (SimCor) and (iii) clear networking time. Figure 7 presents the breakdown of the total analysis time to the individual sources of delay. It can be seen that networking time is the dominant delay factor as it corresponds to the $70 \%$ of the overall analysis, while it is only $10 \%$ of time related to module coordination and handling and even less dedicated to finite element analysis. Though the latter is clearly a function of the active degrees of freedom, the intensity level and the corresponding material and geometrical non-linearity which would eventually increase finite element-related computational cost especially in the case of a non-seismically isolated bridge, the network communication is still deemed as the most critical factor.

It is also interesting to notice that the total analysis time increases significantly when the modules run in the U.S. and Canada are introduced (Figure 10). This is further verified by the latency rates between the Greek partners (Aristotle University and University Patras), the University of Naples in Italy and the University of Toronto (Canada) and Illinois at UbranaChampaign (U.S.). It is seen that for a 100 megabit network more than $50 \%$ of the latency can 
be attributed to crossing the Atlantic. In fact, it takes 7-10 hops and approximately $60 \mathrm{~ms}$ to link to the last European hop (i.e., Paris or Frankfurt) while more than $70 \mathrm{~ms}$ are spent before connecting to the first transatlantic hop in Toronto. It has to be noted however, that for the particular hybrid test envisioned, it is the time step that is of interest and not the overall experiment time, hence the challenge is to retain the networking time as low as possible and compensate the actual bearing force accordingly.

A final comment that needs to be made is that, at least during the preparatory stage of intercontinental multi-platform analysis, the need for manual action in case of abrupt network or analysis failure is still evident, thus yielding the analysis as not fully resilient. Overall though, it is deemed that extensive calibration of the multi-platform distributed computation has established a level of confidence prior to conducting the final intercontinental hybrid experiment.

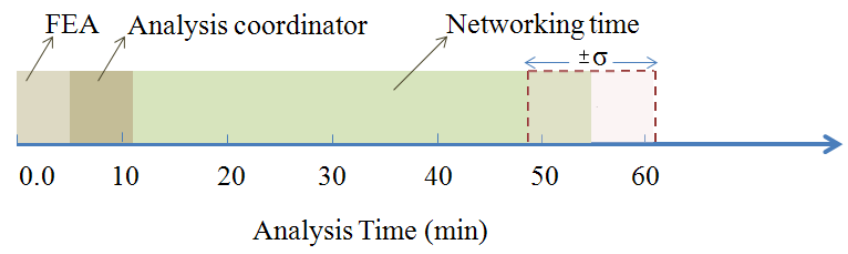

Figure 7: Contribution of various analysis stages to the overall analysis time.

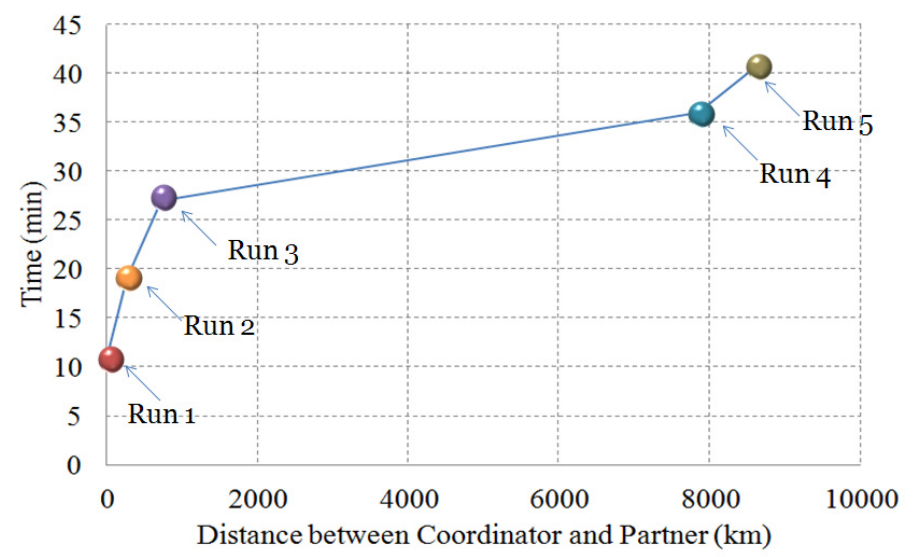

\begin{tabular}{cccccc} 
& Coordinator & Module 1 & Module 2 & Module 3 & Module 4 \\
\hline Run 1 & AUTH & AUTH & AUTH & AUTH & AUTH \\
Run 2 & AUTH & AUTH & AUTH & AUTH & UPATRAS \\
Run 3 & AUTH & AUTH & AUTH & AUTH & UNAPLES \\
Run4 & AUTH & AUTH & AUTH & AUTH & U of T \\
Run 5 & AUTH & AUTH & AUTH & AUTH & UIUC \\
\hline
\end{tabular}

Figure 8: Total analysis time as the distance between the coordinator and the partner increases (communications executed over a 100 megabit network, and latency between AUThessaloniki and University Toronto at 132-

172ms after 10-15 intermediate hops, respectively).

\section{CONCLUSIONS}

This study describes the procedure followed to investigate the conditions under which the implementation of a geographically distributed hybrid simulation concept becomes robust, repetitive and resilient, in the case of an intercontinental experiment among five partners (three in Europe, one in Canada and one in the U.S.). A four span, seismically isolated, reinforced concrete bridge of a total length of $110.40 \mathrm{~m}$ was assessed under earthquake loading, implementing, at a preliminary stage, the geographically distributed multi-platform simulation concept. Through an extensive parametric analysis scheme, it was seen that among the various sources of analysis delay, i.e., the geographical distribution of modules, the partners' role in the sub-structured analysis, the daytime the simulation took place, as well as 
pure network connection time, the latter clearly is the most dominating factor. As a result and given the rate-dependency of the bearing that is to be physically tested at the University of Patras during the next stage of hybrid experimentation, careful tuning of the above parameters is of paramount importance. Based on the experience gained, it is also seen that, overall, the concept of multi-platform simulation for earthquake engineering applications between intercontinental partners is fully robust, fully repetitive but only partially resilient, while the foreseen intercontinental hybrid experiment is also expected to be fully repetitive and robust provided that the time step delay is efficiently compensated. Further investigation is currently under progress.

\section{ACKNOWLEDMENTS}

This work carried out was funded by the $7^{\text {th }}$ Framework Programme of the European Commission, under the PIRSES-GA-2009-247567-EXCHANGE-SSI grant (Experimental \& Computational Hybrid Assessment Network for Ground-Motion Excited Soil-Structure Interaction Systems, www.exchange-ssi.net). The authors would like to thank Prof. Luigi di Sarno at the University Sannio, Prof. Alain Pecker at Geodynamique et Structures and particularly Prof. Stathis Boussias at University Patras, Prof. Oh-Sung Kwon at University of Toronto and Prof. Amr Elnashai at University of Illinois at Urbana-Champaign for their precious contribution to the distributed analysis sequence and the preparation of the hybrid experinment.

\section{REFERENCES}

[1] O.-S. Kwon, N. Nakata, A. S. Elnashai, and B. F. Spencer, “A framework for multi-site distributed simulation and application to complex structural systems," Journal of Earthquake Engineering, vol. 9, no. 5, pp. 741-753, 2005.

[2] P. Pan, M. Tada, and M. Nakashima, "Online hybrid test by internet linkage of distributed test-analysis domains," Earthquake Engineering \& Structural Dynamics, vol. 34, no. 11, pp. 1407-1425, Sep. 2005.

[3] Y. Takahashi and G. Fenves, "Software framework for distributed experimentalcomputational simulation of structural systems," Earthquake Engineering \& Structural Dynamics, vol. 35, no. 3, pp. 267-291, Mar. 2006.

[4] V. Saouma, D.-H. Kang, and G. Haussmann, "A computational finite-element program for hybrid simulation," Earthquake Engineering \& Structural Dynamics, vol. 41, pp. 375-389, 2012.

[5] Q. Wang, J.-T. Wang, F. Jin, F.-D. Chi, and C.-H. Zhang, "Real-time dynamic hybrid testing for soil-structure interaction analysis," Soil Dynamics and Earthquake Engineering, vol. 31, no. 12, pp. 1690-1702, Dec. 2011.

[6] G. Haussmann, "Evaluation of OpenFresco and SIMCOR for Fast Hybrid Single Site Simulation, CU-NEES-07-02, University of Colorado," 2007.

[7] B. F. Spencer, A. S. Elnashai, K. Park, and O.-S. Kwon, "Hybrid Test Using UISimCor, Three-Site Experiment," 2006.

[8] O.-S. Kwon and A. S. Elnashai, "Seismic analysis of meloland road overcrossing using multiplatform simulation software including SSI," Journal of Structural Engineering, vol. 134, no. 4, pp. 651-660, 2008.

[9] S. Gunnay and A. Schellenberg, "Continous Intercontinental Hybrid Testing." pp. 1-7, 2012. 
[10] O.-S. Kwon, A. S. Elnashai, B. F. Spencer, and K. Park, "UI-SIMCOR: A global platform for hybrid distributed simulation," in 9th Canadian Conference on Earthquake Engineering, 2007, no. June, pp. 139-149.

[11] Ministry of Public Works (1999) "Circular E39/99, Guidelines for the seismic analysis of bridges" (in Greek).

[12] Ministry of Public Works of Greece, Greek Seismic Code-EAK 2000, Athens, 2000 (amended June 2003) (in Greek).

[13] CEN (Comité Européen de Normalisation) "Eurocode 8: Design of structures for earthquake resistance. Part 2: Bridges". EN 1998-2, Brussels., 2004.

[14] A. S. Elnashai, V. Papanikolaou, and D. Lee, "Zeus NL - A System for Inelastic Analysis of Structures," Univ. of Illinois at Urbana-Champaign, 2002.

[15] F. McKenna, G. Fenves, and M. Scott, "Open system for earthquake engineering simulation," University of California, Berkeley, 2002.

[16] F. Filippou and M. Constantinides, "FEDEASLab Getting Started Guide and Simulation Examples," 2004.

[17] K. Hibbit and N. Sorenson, “ABAQUS ver. 6.6, User's Manual,” Pawtucket, USA, 2006.

[18] F. Naeim and J. M. Kelly, Design of Seismic Isolated Structures. N.Y.: Wiley \& Sons, Inc., 1999.

[19] Caltrans, "Seismic Design Criteria Version 1.6," California Department of Transportation: Sacramento, CA, U.S., 2010.

[20] ATC, "Improved seismic design criteria for California bridges," Redwood City, California, Report No. ATC-32, 1996., 1996.

[21] O. N. Taskari and A. G. Sextos, "Stiffness and Ultimate Capacity of Typical Abutment- Embankment Systems," in 15th World Conference on Earthquake Engineering, 2012, no. 1987. 